\title{
Barriers to Mathematics Achievement in Brunei Secondary School Students: Insights into the Roles of Mathematics Anxiety, Self-Esteem, Proactive Coping, and Test Stress
}

\author{
Malai Hayati Sheikh Hamid ${ }^{1}$, Masitah Shahrill ${ }^{1}$, Rohani Matzin ${ }^{1}$, Salwa Mahalle ${ }^{1}$ \& Lawrence Mundia ${ }^{1}$ \\ ${ }^{1}$ Sultan Hassanal Bolkiah Institute of Education, Universiti Brunei Darussalam, Jalan Tungku Link, Bandar Seri \\ Begawan, Brunei Darussalam \\ Correspondence: Malai Hayati Sheikh Hamid, Sultan Hassanal Bolkiah Institute of Education, Universiti Brunei \\ Darussalam, Jalan Tungku Link, Gadong BE 1410, Bandar Seri Begawan, Brunei Darussalam. Tel: \\ 673-246-3001. Fax: 673-246-1003. E-mail: hayati.hamid@ubd.edu.bn
}

Received: August 7, $2013 \quad$ Accepted: September 26, $2013 \quad$ Online Published: October 11, 2013
doi:10.5539/ies.v6n11p1
URL: http://dx.doi.org/10.5539/ies.v6n11p1

\begin{abstract}
The cross-sectional field survey examined the roles of mathematics anxiety, self-esteem, proactive coping, and test stress in mathematics achievement among 204 (151 females) randomly selected Year 8-10 Brunei secondary school students. The negative dimensions of mathematics anxiety, self-esteem, and proactive coping correlated negatively with mathematics achievement and were both poor predictors of and barriers to mathematics achievement. Both test stress components (intrusive and avoidance) also related negatively with mathematics grades and were poor predictors of mathematics achievement. In addition, females scored significantly higher on negative self-esteem and intrusive stress variables than males. Furthermore, mathematically less able students scored significantly higher on the negative mathematics anxiety and negative self-esteem domains than more able peers. Moreover, positive proactive coping was a good predictor of mathematics achievement. Overall, the findings have practical significance indicating psychological areas where attention, counselling efforts and educational interventions need to be directed to help the at-risk and vulnerable students.
\end{abstract}

Keywords: barriers, mathematics achievement, mathematics anxiety, self-esteem, proactive coping, test stress, secondary school students

\section{Introduction}

Mathematics is one of the challenging subjects in which Brunei primary and secondary school students often perform poorly. There is currently general concern about poor examination results in Brunei (see Mohd, 2007). With scant research on the problem, the causes of low performance in mathematics are not quite clear. Haq and Mundia (2012) suspect teachers' inability to idnetify students with special needs as one of the possible contributing factors. On the other hand, Ladis (2009) blamed low results on poor teaching skills. Previous research by Wong, Omar, and Mak (2004) noted a variety of mathematics problems that young students in Brunei preschools have such as not understanding the concepts. For students in Brunei primary and secondary schools the problems have been observed to be due to lack of proper understanding of mathematical language and misinterpretation of mathematical concepts (Anit \& Suffolk, 2001; Chin \& Clements, 2001; Vaiyatvutjamai \& Clements, 2004). Recent research has identified similar mathematical conceptual problems in both primary and secondary schools students (Mundia, 2010a; Mundia, 2012a).

A number of suggestions have been made to solve the problem. They include several ideas on preventing math anxiety (Martinez, 1987) and the on-going efforts in Brunei to develop mathematics screening tests for lower and upper primary school students. The purpose of these instruments is to diagnose mathematics learning problems for young children. Other recent measures to address the problem have involved the implementation of the new National Education System for the 21st Century code-named in Malay language as SPN21 curriculum (Ministry of Education, 2008; Mundia, 2009), and the reform of the school assessments that led to the introduction of the school-based assessment for learning, SBAfL (Mundia, 2009; 2010b). Studies have also emphasized the importance of using suitable methods, such as cooperative learning, to teach mathematics to slow learners (Ahmad, 2001; Veloo \& Diah, 2004). It has further been suggested that teachers should use instructional 
techniques that improve students' attitudes towards mathematics (Rajagopal \& Bakar, 2004; Haq \& Mundia, 2012). Improving academic achievement through teacher education reforms has also been the goal of Brunei. It is hoped that the on-going changes in Brunei teacher education policy and programs will address some of the quality issues in teacher education (Mundia, 2012b; Mundia, 2012c; Tait \& Mundia, 2012).

\subsection{Mathematics Anxiety and Academic Achievement}

Mathematics anxiety (MA) is an intense emotional and irrational fear of mathematics based on unrealistic feelings of frustration, hopelessness, and helplessness associated with repeated failure or lack of experience of success. In the literature, MA has long been suspected to have adverse impact on mathematics learning and performance in students. For example, a study on statistics (a branch of mathematics), found that mathematics anxiety had a number of negative facets or elements on overall performance in mathematics such as procrastination, interpretational anxiety, test and class anxiety, fear of asking for help, fear of failure, task aversion, negative computational self-concept, and fear of the statistics instructor (Onwuegbuzie, 2001). MA is thus a non-productive experience that harms future learning as the student's inability to do numerical operations leads to psychological pain, discomfort, reduced interest and motivation as well as avoidance of mathematics and mathematics lessons (Richardson \& Suinn, 1972; Mathison, 1977). Previous research indicates that mathematics anxiety is rooted largely in teaching, teachers and poor academic performance (Williams, 1988). For example, Sloan (2010) found that mathematics anxiety decreases after taking a course in mathematics but this probably applies more to the successful learners. The intellectual factors that affect math anxiety include learning styles, persistence, self-doubt, and dyslexia (Harper and Daane, 1998; Trujillo and Hadfield, 1999). There are several ways mathematics anxiety may be reduced. One of them is to help learners to identify the various ways they conceptualize mathematics and then assist them to notice their faulty conceptualizations (Chiu, 2012). Recently, Daneshamooz and Alamolhodaei (2012) found that mathematics anxiety had a significant negative correlation with mathematics performance.

\subsection{Self-Esteem and Academic Performance}

Earlier research (e.g. Rosenberg, 1965; Fleming \& Courtney, 1984) showed that self-esteem had two dimensions, positive and negative, and that it had positive links or connections with academic success (e.g. Fogiel, 1989). However, new research disputes this latter claim and suggests that the relationship between self-esteem and academic achievement might be mediated by other variables. For example, Aryana (2010) found a significant positive relationship between self-esteem and academic achievement in pre-university students but no big gender differences in their self-esteem scores. The results of this study showed that the two genders' difference in academic achievement was not caused by differences in self-esteem but rather by differences in academic motivation (Aryana, 2010). Another relatively recent previous study (Tella, 2007) found that gender discrepancy in mathematics achievement was significant when the influence of motivation (e.g. need for achievement, nAch) was evaluated in female and male students. In their review study, Baumeister et al. (2003) argued that the modest correlations between self-esteem and school performance did not indicate that high self-esteem lead to good performance. Instead, high self-esteem was partly the result of good school performance.

\subsection{Proactive Coping and Academic Achievement}

Academic achievement appears to be facilitated and fostered by many factors including motivation and coping styles for stressful situations. The role of motivation in academic achievement is, however, made complex by the fact that there are many different types of motivation and motivation appears to be mediated by many related and non-related factors such as interest, locus of control, self-esteem, self-efficacy, and culture. In their study, Zhu and Leung (2011) found that both intrinsic and extrinsic motivation contributed to East Asian students' mathematics achievement in an additive fashion, whereas extrinsic-related motivation appeared to have a detrimental effect on their Western counterparts' learning. These researchers explored possible reasons for the difference from a cultural view point. According to Sagiea (1994) achievement motivation is not a unitary but rather a multifaceted construct. The results of factor analysis and smallest space analysis in this study demonstrated that, instead of one unitary disposition, there were six separate components of achievement motivation: e.g. confronting uncertainty, facing difficulties, assuming personal responsibility, calculating risks, solving problems, and striving for perfection (Sagiea, 1994).

Burton and Nelson's (2010) two-stage research sought to understand variables that influence well-being and success at university. Study 1 examined the relationships between general self-efficacy, proactive attitude, proactive coping, academic achievement and self-reported adjustment. The results of Study 1 showed, among other findings, that both general self-efficacy and proactive coping were significant predictors of GPA. These findings provide implications for transition programs for first year students. 
According to Nixon et al. (2010) coping styles are often delineated into: (a) problem-focused coping (PFC), aimed at taking action to change or ameliorate the stressor; (b) emotion-focused coping (EFC), aimed at modifying the negative emotions generated by the stressor; and (c) avoidant coping (AC), aimed at avoiding the stressor altogether. Nixon et al. (2010) found that the PFC coping strategy was related to students' school achievement in Australia.

\subsection{Test Stress and Academic Achievement}

Stress is one of those many factors that in the present study are hypothesized to have negative effects on academic achievement. Two studies are presented here to support this claim. Malik and Balda's (2006) study aimed at finding out if any relationship existed between psychological stress and academic achievement in high IQ adolescents. Academic achievement was found to be negatively and significantly correlated with all types of stress assessed in this study. Such negative relationship between academic achievement and psychological stress was also reported by Ford (1993), Moore (1997) and Alatorre and Reyer (1999).

\subsection{Objectives of the Present Study}

The current study explored the relationship between mathematics anxiety, self-esteem, proactive coping, and test stress to performance in mathematics among secondary school students. Specifically, the main objective of the present study was to determine the linkages that mathematics anxiety, self-esteem, proactive coping, and test stress have with mathematics achievement in a Brunei sample of secondary school students. The results of the present study might be useful in informing student counselling and educational intervention efforts related to mathematics.

\section{Method}

The study used the cross-sectional field survey research strategy to investigate the problem. Under this procedure, we collected data from students in different grades or levels of secondary school in the Brunei education system. The field survey research design differs from the telephone, online, and postal survey techniques in that the researcher (or research assistant) has to personally go into the fields (relevant educational institutions in the present study) to collect the data. The rationale and justification for employing this survey mode was two-fold. First, the researchers wanted to involve as many secondary school students as possible across three educational levels. Second, the investigators wanted to give on-the-spot help to respondents who needed assistance in completing the research instruments properly so as to increase the number of usable returns.

\subsection{Sample}

Using a list of government secondary schools from the Ministry of Education, four schools were randomly chosen for this study. The selected schools represented two of the four regions of Brunei. From these schools, 223 participants were selected randomly for purposes of the study. Of these, 8 students did not meet the inclusion criteria for the study due to having too many missing values on their self-report data collection instruments. A further 11 students (all in Form 1) were also excluded from the study for two reasons. First, this subsample was too small for purposes of computing the required comparative statistics such as the T-tests. Second, the Form 1 students did not seem to understand the English data collection instruments well and their removal from the study improved the reliability of the scales. The remaining 204 students comprised of 151 (74\%) females and 53 (26\%) males. The sample consisted of 106 (52\%) Form 2s, 54 (26\%) Form 3s, and 44 (22\%) Form 4s. Form 2-to-Form 4 represent the second-to-fourth year of secondary education respectively, in Brunei Darussalam. Thus Form 2 is equivalent to Year 8 or Grade 8 in other countries' education systems. In terms of Age, the oldest and youngest research participants were aged 18 and 14 years respectively. Overall, only $45(22 \%)$ of the participants self-reported that they liked mathematics while the rest (majority) were most interested in other subjects. On another separate biographical item, only $61(30 \%)$ students voluntarily indicated that they performed well in mathematics. Additional biographical information pertaining to the composition and characteristics of the participants is presented in Table 1. 
Table 1. Demographical characteristics of the participants ( $\mathrm{N}=204)$

\begin{tabular}{llll}
\hline Characteristics & $\begin{array}{l}\text { Form 2 } \\
(\text { Grade } 8) \\
\mathrm{n}=106\end{array}$ & $\begin{array}{l}\text { Form 3 } \\
(\text { Grade } 9)\end{array}$ & $\begin{array}{l}\text { Form 4 } \\
\text { (Grade 10) } \\
\mathrm{n}=44\end{array}$ \\
\hline Females $(\mathrm{n}=151)$ & 82 & 36 & 33 \\
\% of subsample & 77 & 67 & 75 \\
\% of whole sample & 40 & 18 & 16 \\
Males $(\mathrm{n}=53)$ & 24 & 18 & 11 \\
\% of subsample & 23 & 33 & 25 \\
\% of whole sample & 12 & 9 & 5 \\
Mean age & 14.320 & 14.790 & 15.360 \\
Standard deviation & 0.770 & 0.950 & 1.030 \\
\hline
\end{tabular}

\subsection{Instruments}

Data for the study were collected by one instrument divided into five sections (A - E). Part A was a biographical questionnaire while the rest (Parts B-E) were Likert-type self-report psychological scales. All the four psychological inventories were bi-dimensional with both positive and negative statements. Literature in previous studies (e.g. Bai, 2011) indicated that bi-polar affects underpin most of the natural emotions, thoughts, feelings, beliefs, and behaviours for humans. Besides this, positively and negatively worded items help investigators to determine whether the research participants developed a response set or bias. In view of these associated benefits, the use of psychological questionnaires with both positively and negatively worded items is common.

Part A of the instrument for the present study consisted of a 7-item personal information questionnaire constructed by the researcher. This section collected demographic information such as gender, age, participants' educational level or class as well as interest in selected school subjects.

Part B contained the 14-item Mathematics Anxiety Scale-Revised, MAS-R (Bai, Wang, Pan, \& Frey, 2009). All the items in this new inventory had 5-point Likert-type scales (ranging from $1 \mathrm{SD}$ to $5 \mathrm{SA}$ ). Seven of the items were positively worded while the other half (7) were negatively phrased. The negatively stated items were reverse scored. Bai et al (2009) and Bai (2011) determined the psychometric properties of the positive and negative items separately in form of subscales. Both the validation study for MAS-R (Bai et al, 2009) and the cross-validation study (Bai, 2011) reported the MAS-R to have had good internal consistency reliability as well as satisfactory construct validity. As suggested or implied by its name, MAS-R measures mathematics anxiety (MA). Following the procedures used by Bai et al (2009) and Bai (2011) the positive and negative items for the MAS-R scale were designated as two subscales (called Positive MA and Negative MA) in the present study.

Part C comprised of the old but classical or seminal 10-item Self-esteem Scale, SE (Rosenberg, 1965) which is still widely used. Half of the items in this scale are negatively stated and reverse scored. Items in this inventory had 4-point Likert-type scales (ranging from $1 \mathrm{SD}$ to $4 \mathrm{SA}$ ). This short and well-established self-esteem scale measures an individual's feelings of self-worth. Employing the procedures used by Bai et al (2009) and Bai (2011) the positive and negative items for SE scale were also designated as two subscales (referred to as Positive SE and Negative SE).

Part D presented the 14-item Proactive Coping scale, PC (Greenglass et al., 1999). Eleven items of this questionnaire were written in the positive and three in the negative direction, requiring both positive and negative scoring respectively. The items were rated on 5-point Likert-type scales (ranging from 1 Not at all true; to 5 Completely true). Based on the procedures used by Bai et al (2009) and Bai (2011) the positive and negative items for the PC scale formed two subscales (labelled as Positive PC and Negative PC). Higher scores on the proactive coping scale and subscales indicate high levels of proactive coping ability to alleviate stress.

Part E was composed of the 15-item Impact of Event scale, IE (Horowitz et al., 1979). This is also a widely used and well-established instrument which has been translated into many languages world-wide. The IE scale did not have positive and negative items. Instead, it had two categories of items, 7 of which were termed as "intrusive" and another 8 items labelled as "avoidance" by Horowitz, et al. (1979). In the present study, the items for this instrument were scored following 4-point Likert-type scales (ranging from 1 Not at all; to 4 Often). The intrusive and avoidance items were treated as forming two subscales (known as Intrusive IE and Avoidance IE). This scale measures stress arising from a recent stressful event in a person's life (e.g. recent mathematics examination 
as a source of stress). The stress measured by the IE scale in the present study may have occurred before, during, or after the test.

We also collected the respondents' continuous assessment math grades for the previous academic term from school records. In predictions of academic success, previous research has used either grades or grade point averages (GPA) as measures of academic achievement or performance. Two illustrative examples here are Broussard (2002) who used grades as an indicator of academic achievement and Rickets (2003) who employed GPA as an index of academic performance. Although the math grades used in the present study were obtained from different assessment tasks, they were (regardless of the educational level and school) standardized in the whole Brunei education system (where $\mathrm{A}=80-100 \% ; \mathrm{B}=70-79 \% ; \mathrm{C}=60-69 \% ; \mathrm{D}=50-59 \% ; \mathrm{E}=40-49 \%$; and $\mathrm{F}=0-39 \%$ ). The distribution of math grades in the present study for all the 135 participants across the four levels of secondary education (Form 2 to Form 4 ) ranged from A to F. The letter grades were then converted to their numerical equivalents (e.g. $\mathrm{A}=5 ; \mathrm{B}=4 ; \mathrm{C}=3 ; \mathrm{D}=2 ; \mathrm{E}=1$; and $\mathrm{F}=0$ ) and used as a grouping variable. Being sensitive data and for ethical reasons, the grades were analysed and reported only at the group level. In the present study, high (top) math achievers were students who obtained A-B-C grades (coded 2 for analysis purposes) while low (bottom) achievers were those who got D-E-F grades (coded 1). The majority of the participating students scored in the middle of the range (average level) with C-D grades. The descriptive statistics and reliability coefficients for the psychological scales are presented in Table 2.

Table 2. Split-half reliability and discriminant validity of the main scales $(N=204)$

\begin{tabular}{lllll}
\hline Variables & 1 & 2 & 3 & 4 \\
\hline $\begin{array}{l}\text { Mathematics Anxiety (MA) } \\
\text { Self-esteem (SE) }\end{array}$ & 1 & & & \\
& 0.136 & 1 & & \\
$\begin{array}{l}\text { Proactive Coping (PC) } \\
\text { Impact of Event (IE) }\end{array}$ & $0.223^{* *}$ & $0.147^{*}$ & 1 & \\
Math Achievement & & & & \\
& $0.140^{*}$ & 0.097 & $0.229^{* *}$ & 1 \\
& 0.031 & $-0.187^{* *}$ & $0.141^{*}$ & -0.141 \\
Mean & 49.245 & 27.794 & 46.808 & 37.421 \\
SE mean & 0.398 & 0.250 & 0.560 & 0.489 \\
Standard deviation & 5.688 & 3.572 & 8.005 & 6.986 \\
Split-half reliability & 0.700 & 0.820 & 0.730 & 0.760 \\
\hline
\end{tabular}

The correlations in Table 3 may be interpreted in many ways. The low and non-significant correlations suggest that the scales were measures of different constructs and did not replicate each other. For these scales, the correlations provide good quantitative evidence for the scales' discriminant validity. The low but significant correlations imply that the scales (to a small extent) might be overlapping and measuring the same construct but the amount of duplication or common variance $\left(\mathrm{r}^{2}\right)$ is little and negligible. The paired subscales are thus not redundant and can be said to have satisfactory discriminant validity and low convergence validity. A careful look at these inter-subscale correlations revealed a three-pattern relationship. As expected, positively anchored subscales tended to correlate positively and sometimes significantly with each other. Similarly, negative oriented subscales also largely correlated positively and at times significantly with each other as presumed. On the other hand, negatively and positively scales all correlated negatively and often significantly with each other.

The questionnaire scores and test grades used in the present study were considered to have had good ecological validity in that students obtained them in their respective schools. There was no evidence suggesting that students responded to questionnaire items cautiously and defensively. In addition, students obtained math test grades as part of continuous assessment. Such assessments exert less pressure, anxiety, tension, and stress to students compared to the abrasive demands of the final examinations. The present study was also deemed to have both practical significance and social validity in that it was seeking answers or solutions to a national problem regarding barriers to mathematics achievement. As such, the research was acceptable and valuable to many educational stakeholders in Brunei including students, parents, teachers, and the Ministry of Education. 
Table 3. Inter-correlations of subscales and mathematics achievement $(\mathrm{N}=204)$

\begin{tabular}{|c|c|c|c|c|c|c|c|c|c|}
\hline Factors & 1 & 2 & 3 & 4 & 5 & 6 & 7 & 8 & 9 \\
\hline Math Achievement & 1 & & & & & & & & \\
\hline Negative MA & $-0.258 * *$ & 1 & & & & & & & \\
\hline Positive MA & $0.182 * *$ & -0.118 & 1 & & & & & & \\
\hline Negative SE & $-0.308 * *$ & $0.338 * *$ & $-0.187 * *$ & 1 & & & & & \\
\hline Positive SE & 0.063 & -0.064 & $0.217 * *$ & -0.022 & 1 & & & & \\
\hline Negative PC & $-0.154^{*}$ & $0.251 * *$ & $-0.198 * *$ & $0.320 * *$ & $-0.160 * *$ & 1 & & & \\
\hline Positive PC & $0.205^{* *}$ & -0.061 & 0.256 & -0.113 & $0.286^{* *}$ & 0.009 & 1 & & \\
\hline Intrusive IE & -0.041 & 0.021 & $0.143 *$ & -0.022 & $0.170^{*}$ & 0.003 & $0.303^{* *}$ & 1 & \\
\hline Avoidance IE & -0.026 & $-0.261 * *$ & -0.094 & $0.156^{*}$ & -0.084 & $0.1833 * *$ & 0.034 & $0.343 * *$ & 1 \\
\hline Mean & 1.573 & 23.848 & 25.509 & 13.583 & 14.210 & 9.019 & 37.789 & 17.235 & 20.186 \\
\hline Standard deviation & 1.482 & 4.852 & 4.167 & 2.664 & 2.439 & 2.657 & 7.528 & 4.210 & 4.313 \\
\hline
\end{tabular}

\subsection{Data Analysis}

Data on the research protocols were coded and scored according to instructions provided by the author(s) of each instrument. Negative items on three main scales (MA, SE, and PC) were reverse-scored prior to analyses. As pointed above, the IE scale did not have positive and negative items as it had only two sets of items called "intrusive" and "avoidance". In view of this, reverse scoring was not applied to IE scale items. Biographical data were analysed descriptively. The participants' mathematics letter grades were changed to nominal values or ordinal ranks (ranging from: $\mathrm{A}=5 ; \mathrm{B}=4 ; \mathrm{C}=3 ; \mathrm{D}=2 ; \mathrm{E}=1 ;$ to $\mathrm{F}=0$ ) and entered after scoring them in this fashion. These numerical grades were then used in the computation of rank-order correlations between the total scores for each scale and mathematics performance (numerical grades). The numerical grades were also used as a grouping variable to compute T-test statistics for independent groups. Data from all the four psychological tests were analysed by descriptive, nonparametric, and inferential or parametric statistics. Descriptive and nonparametric statistics included the frequencies, percentages, mean, standard deviation, and Spearman's rank-order correlations. The inferential/parametric statistics included t-tests for independent groups, and multiple regression analysis. All data analyses were performed on SPSS Version 17.0 (see Kirkpatrick \& Feeney, 2011 for explanations of this version). We ensured that no statistical assumptions were violated on all data analyses.

\subsection{Procedures}

Permission to conduct the study in schools was obtained from school authorities and class teachers on behalf of the students and parents (loco parentis). Prior to administering the instruments, the researchers verbally explained to the participants the purpose of the study and the ethical conditions or requirements for being involved in the study. This discussion centred on the rights of the participants surrounding issues such as voluntary participation, privacy, anonymity, confidentiality, physical and psychological harm, debriefing, and informed consent. No deception was used or involved in this study. Student participants were given ample time to reflect on and to withdraw from the study if they felt uncomfortable with the research's purposes and objectives. The selected students voluntarily agreed to participate in the study. In addition, the participants also permitted the researchers to use the obtained data in other psychological investigations such as being included in various case studies. Being highly sensitive private information, all the mathematics grades were kept strictly confidential, analysed and reported only at the group level. To protect the participants further, the constant value was omitted in Table 6 (multiple regression analysis) to prevent readers from reconstructing the grades for participants. With regard to English language problems, the meanings of difficult English words, sentences and phrases in the instruments were verbally explained to the participants. Furthermore, students in Brunei secondary schools are taught in English language and have participated in many research studies that required them to complete self-report scales / questionnaires in English. Moreover, the items in all the five questionnaires for this study were written in simple English requiring only primary school education. The researchers therefore deemed it not necessary to translate the instruments into Bahasa Melayu (Brunei's main and official language). The study met the ethical requirements for using human participants in research stipulated by the University of Brunei Darussalam, the Government of Brunei, and the Helsinki Declaration. 


\section{Results}

The results of the study are presented below according to the objectives of the investigation outlined above and the type of data collected.

\subsection{Comparison of All the Participants' Mathematics Anxiety, Self-Esteem, Proactive Coping, and Test Stress Scores}

The students' mean scores, standard and standard deviations on the main scales and subscales are presented at the bottom of Table 2 and Table 3 respectively. These scores cannot be directly compared across the scales as they were not standardized. In addition, the self-esteem (SE) scale had the lowest standard error while the proactive coping (PC) variable had the highest standard deviation and most varied responses (Table 2). It should, however, be noted that all the differences between the mean scores in Table 2 and were not statistically significant.

\subsection{Gender Differences in Mathematics Anxiety, Self-Esteem, Proactive Coping, and Test Stress Scores on the Main Scales}

No significant difference was detected for the whole sample between females and males on the main mathematics anxiety scale: $\mathrm{t}(202)=0.869, \mathrm{p}>.05\left[\mathrm{M}_{1}=49.450, \mathrm{SD}_{1}=5.999 ; \mathrm{M}_{2}=48.660, \mathrm{SD}_{2}=4.694\right]$. However, the whole sample differed significantly on the main self-esteem scale by gender: t $(202)=2.680, p$ $<.01\left[\mathrm{M}_{1}=28.185, \mathrm{SD}_{1}=3.020 ; \mathrm{M}_{2}=26.679, \mathrm{SD}_{2}=4.668\right]$. The difference between the two genders on the main proactive coping scale was statistically insignificant: $\mathrm{t}(202)=0.097, \mathrm{p}>.05\left[\mathrm{M}_{1}=46.841, \mathrm{SD}_{1}=8.361\right.$; $\left.\mathrm{M}_{2}=46.717, \mathrm{SD}_{2}=6.965\right]$. On the main impact of event scale, the difference between the two genders' mean scores neared significance level: $\mathrm{t}(202)=1.870, \mathrm{p}>.05\left[\mathrm{M}_{1}=37.960, \mathrm{SD}_{1}=6.800 ; \mathrm{M}_{2}=35.886, \mathrm{SD}_{2}=7.339\right]$.

Gender differences on the eight subscales and mathematics achievement are presented in Table 4. Significant gender differences were obtained on only two subscales (Negative SE and Intrusive IE) where females scored much higher than their male counterparts on both variables. This difference was masked by composite scores in the above analyses for the whole scales.

Table 4. Differences in psychological attributes and math achievement by gender $(\mathrm{N}=204)$

\begin{tabular}{|c|c|c|c|c|c|c|}
\hline \multirow[t]{2}{*}{ Factors } & \multicolumn{2}{|c|}{ Females $(\mathrm{n}=151)$} & \multicolumn{2}{|c|}{ Males $(\mathrm{n}=53)$} & \multirow{2}{*}{$\begin{array}{l}\mathrm{t} \\
(\mathrm{df}=202)\end{array}$} & \multirow{2}{*}{$\begin{array}{l}\mathrm{P} \\
\text { (2-tailed) }\end{array}$} \\
\hline & $\overline{\text { Mean }}$ & SD & Mean & SD & & \\
\hline Negative MA & 24.046 & 4.722 & 23.283 & 5.212 & 0.985 & 0.326 \\
\hline Positive MA & 25.569 & 4.535 & 25.339 & 2.901 & 0.345 & 0.731 \\
\hline Negative SE & 13.814 & 2.541 & 12.924 & 2.914 & 2.110 & $0.036^{*}$ \\
\hline Positive SE & 14.371 & 2.362 & 13.754 & 2.615 & 1.588 & 0.114 \\
\hline Negative PC & 9.092 & 2.738 & 8.811 & 2.426 & 0.662 & 0.509 \\
\hline Positive PC & 37.748 & 7.847 & 37.905 & 6.602 & -0.131 & 0.896 \\
\hline Intrusive IE & 17.609 & 4.142 & 16.169 & 4.259 & 2.161 & $0.032 *$ \\
\hline Avoidance IE & 20.351 & 4.186 & 19.717 & 4.667 & 0.920 & 0.359 \\
\hline Math Achievement & 1.516 & 1.482 & 1.735 & 1.482 & -0.926 & 0.355 \\
\hline
\end{tabular}

$* \mathrm{P}<.05$ (two-tailed)

\subsection{Differences in Mathematics Anxiety, Self-Esteem, Proactive Coping, and Test Stress by Mathematics Ability}

The differences on the subscales of mathematics anxiety, self-esteem, proactive coping, and impact of event variables were examined between low and high scorers in mathematics. Low math scorers (less able learners) were defined as students who obtained poor mathematics grades (D, E, and F) while high math scorers (more able students) were participants who received higher mathematics grades (A, B, and C). The high scorer category consisted of 62 students only while the rest and majority of the participants (142) comprised the low scoring group. No significant difference was obtained between the two arbitrary ability groups on any of the four main psychological scales $(\mathrm{p}>.05)$. However, the two groups differed significantly on at least three of the eight subscales presented in Table 5 below. Less able students scored significantly higher on negative mathematics 
anxiety (Negative MA, the subscale consisting of negatively worded items) and negative self-esteem (Negative $\mathrm{SE}$, the subscale comprising of negatively phrased items) than their more able counterparts. Mathematically more able students scored significantly higher on the positive proactive coping subscale (Positive PC, a subscale made up of positively described items) than less able math learners. In general, participants in the two groups scored in the expected direction on six variables (Negative MA, Positive MA, Negative SE, Positive SE, Negative PC, and Positive PC). Surprisingly and contrary to the expectations of the researchers, more able students scored slightly higher than less able participants on Intrusive IE and Avoidance IE although the differences between the two groups on both of these variables were statistically insignificant. Table 5 also shows a high significant difference in mathematics achievement between the two ability groups.

Table 5. Differences in psychological attributes and math achievement by mathematics ability $(\mathrm{N}=204)$

\begin{tabular}{|c|c|c|c|c|c|c|}
\hline \multirow[t]{2}{*}{ Factors } & \multicolumn{2}{|c|}{ High Scores $(n=62)$} & \multicolumn{2}{|c|}{ Low Scores $(\mathrm{n}=142)$} & \multirow{2}{*}{$\begin{array}{l}\mathrm{t} \\
(\mathrm{df}=202)\end{array}$} & \multirow{2}{*}{$\begin{array}{l}\mathrm{P} \\
\text { (2-tailed) }\end{array}$} \\
\hline & Mean & SD & $\overline{\text { Mean }}$ & SD & & \\
\hline Negative MA & 22.725 & 5.138 & 24.338 & 4.656 & -2.203 & $0.029^{*}$ \\
\hline Positive MA & 26.258 & 3,732 & 25.183 & 4.314 & 1.703 & 0.090 \\
\hline Negative SE & 12.725 & 3.250 & 13.957 & 2.278 & -3.101 & $0.002^{* *}$ \\
\hline Positive SE & 14.371 & 2.656 & 14.140 & 2.344 & 0.619 & 0.537 \\
\hline Negative PC & 8.645 & 2.096 & 9.183 & 2.859 & -1.331 & 0.184 \\
\hline Positive PC & 39.419 & 6.912 & 37.077 & 7.697 & 2.060 & $0.041 *$ \\
\hline Intrusive IE & 17.241 & 3.651 & 17.232 & 4.444 & 0.015 & 0.988 \\
\hline Avoidance IE & 20.483 & 4.139 & 20.056 & 4.394 & 0.650 & 0.516 \\
\hline Math Achievement & 3.387 & 0.775 & 0.781 & 0.907 & 19.670 & $0.000^{* *}$ \\
\hline
\end{tabular}

$* \mathrm{P}<.05$ (two-tailed)

$* * \mathrm{P}<.05$ (two-tailed)

\subsection{Prediction of Mathematics Achievement from Mathematics Anxiety, Self-Esteem, Proactive Coping, and Test Stress Scores}

Three approaches were made at determining the links between mathematics anxiety, self-esteem, proactive coping, and test stress with mathematics achievement in the present study. First, the correlations between each of the four full main scales and mathematics achievement in Table 2 indicate the extent to which these variables might predict achievement in mathematics. The present study peered into the predictive ability or behaviour of the four main scale variables (MA, SE, PC, and IE) investigated. Although the resulting model was statistically significant $[F(8,203)=3.668, p<.01, R=0.262$, $R$ Square $=0.069]$, only two variables (SE and PC) related significantly with mathematics achievement and the whole model accounted for only $7 \%$ of the variance in predicting mathematics performance. The SE variable had a negative coefficient $(B=-0.088, p<.01)$ possibly due to the strong influence of Negative SE while PC had a positive impact though at a lower level of significance $(B=0.034, p<.05)$ probably due to the strong influence of Positive PC. Based on these connections, there was only one possible good predictor of mathematics achievement (proactive coping) but the relationship was at a low level of significance $(\mathrm{p}<.05)$. The other three variables were potential barriers to mathematics achievement. Second, the correlations between each of the eight subscales and mathematics achievement in Table 3 also show the degree to which these variables might predict achievement in mathematics. Based on these correlations there were only two factors (Positive MA and Positive PC) that might be good predictors of mathematics achievement. The remaining six subscale variables were likely to be barriers to mathematics achievement. Third, the B and Beta coefficients from multiple regression analysis displayed in Table 6 below also indicate another form of relationship between the subscales (independent variables) and mathematics grades or achievement (dependent variable). Only Positive PC was found to be a good predictor of mathematics achievement with significant positive B and Beta coefficients. On the other hand, three of the eight subscale variables in Table 6 (Negative MA, Negative SE, and Intrusive IE) had significant negative regression coefficients. These variables were potential barriers to mathematics achievement in the present study. As shown in Table 6 this model was significant and accounted for about $18 \%$ of the variance in predicting mathematics achievement. 
Table 6. Multiple regression analysis of six one-dimensional factors on math achievement $(\mathrm{N}=204)$

\begin{tabular}{llllll}
\hline Variables & $\mathrm{B}$ & $\mathrm{SE}_{\mathrm{B}}$ & $\mathrm{Beta}$ & $\mathrm{t}$ & $\mathrm{P}$ \\
\hline Negative MA & -0.054 & 0.022 & -0.178 & -2.495 & $0.013^{* *}$ \\
Positive MA & 0.034 & 0.025 & 0.097 & 1.383 & 0.168 \\
Negative SE & -0.121 & 0.040 & -0.217 & -2.994 & $0.003^{* *}$ \\
Positive SE & 0.001 & 0.043 & 0.001 & 0.021 & 0.983 \\
Negative PC & -0.024 & 0.040 & -0.043 & -0.606 & 0.545 \\
Positive PC & 0.037 & 0.014 & 0.187 & 2.585 & $0.010^{* *}$ \\
Intrusive IE & -0.054 & 0.026 & -0.154 & -2.084 & $0.038^{*}$ \\
Avoidance IE & 0.041 & 0.025 & 0.118 & 1.609 & 0.109 \\
\hline
\end{tabular}

Model:

$\mathrm{F}(8,203)=5.309, \mathrm{P}<.000, \mathrm{R}=0.423, \mathrm{R}$ Square $=0.179$

$* \mathrm{P}<.05$ (two-tailed)

$* * \mathrm{P}<.01$ (two-tailed)

\section{Discussion}

The main implications are briefly discussed below under separate subheadings corresponding to the objectives of the study and the type of data collected.

\subsection{High Math Anxiety and Test Stress}

Evidence from the present study (provided in Tables 2, 3, 4, and 5) suggests that mathematics anxiety and test stress were big problems for most of this sample of Brunei secondary school students. The results embedded in these tables revealed that both math anxiety (MA) and test stress (measured by the IE scale) were relatively high in all the three student cohorts (Forms 2-4). In the present study, Negative MA was found to be a barrier to success or good performance in mathematics for two reasons. First, Negative MA correlated negatively and strongly with mathematics achievement (Table 3). Though correlations do not imply cause-and-effect relationships, this might suggest that harbouring feelings embedded in these negative statements may lead to failure in mathematics (as negative items represent self-defeating attitudes). Second, Negative MA was also a poor predictor of mathematics achievement (Table 6). Previous research (e.g. Daneshamooz \& Alamolhodaei, 2012) also found that overall mathematics anxiety had a significant negative correlation with mathematics performance.

The present study suspected both intrusive and avoidance items in the IE scale to have adverse effects on stress and academic performance. As expected, none of these items related significantly with mathematics achievement. The correlations with mathematics grades for the majority of the IE items (both intrusive and avoidance) were mostly negative and very low (around 0.000 ). Moreover, multiple regression analyses found that both math anxiety and test stress related negatively with mathematics achievement as illustrated by B, Beta, and t-values in Table 6. Malik and Balda's (2006) study also found that academic achievement was negatively and significantly correlated with all forms of stress assessed in their research. Such negative relationship between academic achievement and psychological stress was also earlier reported by Ford (1993), Moore (1997) and Alatorre and Reyer (1999). In an examination-oriented education system such as Brunei's, it is quite possible for mathematics anxiety and test stress scores to remain high throughout a student's time at school since tests produce a lot of anxiety, tension and stress in students. Previous research (Engelbrecht et al., 1993) shows that the use of informal assessments such as portfolios, self-assessments, peer assessments, and problem-based assessments may assist in reducing anxiety and stress levels. Similarly, incorporation of continuous assessment strategies among the student evaluation criteria together with de-emphasis on summative examinations might also help reduce anxiety and stress levels (see Somerset, 1987). Both the informal assessments and continuous assessments produce less tension, anxiety and stress in students (Mundia, 2009; Mundia, 2010b).

\subsection{Gender Differences on MA, SE, PC, IE and Mathematics Achievement}

All the participants differed significantly by gender only on the self-esteem variable: $\mathrm{t}(202)=2.680, \mathrm{p}<.01$ $\left[\mathrm{M}_{1}=28.185, \mathrm{SD}_{1}=3.020 ; \mathrm{M}_{2}=26.679, \mathrm{SD}_{2}=4.668\right]$ where females scored much higher than their male counterparts. However, the gender differences on the eight subscales and mathematics achievement presented in Table 4 were significant on only two variables (Negative SE and Intrusive IE) where females scored much higher than males on both variables. These findings suggest that females need more counselling interventions on 
Negative SE and Intrusive IE than males. However, Aryana (2010) found that a significant difference in pre-university students' academic achievement was not caused by differences in self-esteem (SE) but rather by differences in academic motivation. Furthermore, an earlier study by Baumeister et al. (2003) found that merely boosting SE was not therapeutic and beneficial to improving academic achievement. Indeed, the present study did not find both self-esteem and stress to be good predictors of mathematics achievement (see Table 3 and Table 6). Despite these significant differences on Negative SE and Intrusive IE, the two genders did not differ significantly with respect to mathematics achievement in the present study (Table 4). The study by Tella (2007) found that gender discrepancy in mathematics achievement was significant when the influence of motivation was evaluated in female and male students.

\subsection{Differences in MA, SE, PC, IE by Mathematics Ability}

While the high and low scorers did not differ significantly on the four main domains (MA, SE, PC and IE), they did differ on some of the subscales for the same variables. Evidence from the present study (Table 5) suggests that the less able students performed poorer in mathematics possibly because of the adverse impact of two main barriers (Negative MA and Negative SE) on which they scored significantly higher than their more able peers. Previous studies have found Negative MA to have a harmful influence on mathematics achievement (Bai, 2011; Bai et al., 2009). On the other hand, the variable that best facilitates mathematics achievement and that needs to be fostered in the development and growth of students is Positive PC (see Table 5).

The role of the combined IE dimensions (Intrusive and Avoidance) in mathematics achievement seems to be complex and ambiguous. The finding (in Table 7) that stronger students in mathematics scored slightly higher on the intrusive and avoidance variables than weaker students (though the difference was statistically insignificant), may be interpreted in three different ways. First, the literature says that not all stress is bad. An optimum amount of stress (called good/positive stress or eustress) might be required to keep a person challenged and energized (Selye, 1974). Second, a small number of studies claim that people learn a few good lessons from some aspects of stress such as critical incidence stress, CIS (Werner et al., 1992). Third, there is also the so-called notion of stress-related growth, SRG (Tassie \& Whelan, 2007) which supports the view that people learn and grow from stressful events. Despite these and other small benefits of stress, it appears that the disadvantages of stress far outnumber the advantages. There are many forms of stress (collectively known as negative stress) that are harmful. The three main dangerous types of stress include acute stress, chronic stress and posttraumatic stress disorder (PTSD).

\subsection{Self-Esteem and Proactive Coping}

Unlike Negative SE and Negative PC that related negatively with and acted as barriers to mathematics achievement, Positive SE and Positive PC were salient personality attributes whose development needs to be facilitated and fostered in students (see Table 3 and Table 5). In the present study, many Positive SE and Positive PC items correlated positively and significantly with mathematics achievement grades though not shown in any table in the text for brevity reasons. One recent previous study by Burton and Nelson (2010) found that both general self-efficacy and proactive coping were significant predictors of GPA. In another recent study, Nixon et al. (2010) found that two types of coping strategies with stressful problems (problem-focused and avoidant-focused coping styles) were significantly related to students' school achievement in Australia.

\subsection{Implications for School Counselling, Teacher Education and Assessment Reforms}

Many students who are high on MA and IE variables and low on SE and PC traits may benefit from counselling or psychotherapy. For example, the females might need more counselling on Negative SE and Intrusive IE than males (Table 6). However, the problem with psychotherapy, in a developing country-context such as Brunei, is that there are not many well trained and experienced school counsellors or school psychologists to provide these essential services (Mundia, 2009; Mundia, 2010b). For instance, remedial intervention classes that use cooperative learning strategies might permit less able students to experience success while those that are taught by teachers with realistic expectations of the learners may help to reduce mathematics anxiety and post-test stress.

As pointed out above, the present study identified variables that were barriers to and good predictors of mathematics achievement. Although the multiple regression model (Table 6) that identified these barriers and predictor accounted for only $18 \%$ of the variance in predicting mathematics achievement, the findings of the present study have high practical significance for teacher education and assessment reforms in Brunei. According to Burns (2000) practical significance is more important than statistical significance. Both the pre-service and in-service teacher education programs in Brunei may wish to consider directing more attention and efforts towards sensitizing trainee mathematics teachers about the barriers to and good predictors of 
mathematics achievement. Such mass awareness campaigns should include discussions on the roles of both dimensions of MA, SE, PC and IE as discussed in the present study. In particular, the findings of the present study may be relevant to the on-going teacher education reforms for mathematics instructors as well as the SPN21 curriculum reforms in schools. Unless the school assessments were also reformed concurrently, the present curriculum innovations in Brunei may take longer to succeed (Mundia, 2009; 2010a; 2010b).

\section{Conclusion and Recommendations}

The survey investigated the relationship between MA, SE, PC and IE and mathematics achievement in Brunei secondary school students. As expected, positive dimensions (positively worded items) of the MA, SE, and PC scales correlated positively with math grades while most negative dimensions (negatively stated items) of these scales related inversely with math achievement scores. Both MA and IE were high in all three participant groups. Females were more affected with Negative SE and Intrusive IE than males. Low math scorers (less able students) were more affected by Negative MA and Negative SE than high scorers (more able students). On the positive note, Positive PC was found to be a good predictor of mathematics achievement that needs to be fostered in students. Academic and personal counselling was suggested to help students with high support needs in learning mathematics. The present study probed one of Brunei's worrying educational problems and attempted to identify factors that might help explain poor performance in mathematics. Findings from the present study may be helpful in formulating research questions or hypotheses for future mixed-methods investigations that could shed more light on the problem and its solutions. In addition, it is hoped that the findings of the present study may be of interest to other developing countries especially those in the Southeast Asia region that share similar concerns with Brunei regarding mathematics achievement in schools.

The present study is only the first in a series of three research projects planned by the investigators and intended to identify variables that might help to explain Brunei secondary school students' deficiencies in mathematics achievement. The next two studies will address the role of eight other factors (taken four at a time) in mathematics achievement. The selected constructs for the last two phases of the inquiry are self-regulation, critical thinking, perseverance, self-efficacy, learning styles, locus of control, achievement motivation, and study strategies or skills. It is hoped the three studies may, altogether, provide insights that will be useful in training Brunei mathematics teachers as well as in teaching, assessing and counselling Brunei secondary school students with high support needs in mathematics learning.

\section{Limitations of the Study}

Like other approaches to research, field surveys have both disadvantages and advantages. One of this strategy's major limitations is that the findings may not indicate cause-and-effect relationships among the variables investigated. Another main drawback is that the presence of the investigator during data collection might lead to negative researcher-effects such as encouraging research participants to give socially desirable responses on self-report measures. In addition to these concerns, the present study was also informed by two other limitations. First, since the assessment using the MA, SE, PC and IE scales was neither repeated nor triangulated, the obtained scores and findings may be regarded as exploratory rather than confirmatory. In view of this, the study may be replicated (supplemented with interviews) to complement and verify the findings from the initial survey data. Second, in addition to convergent and discrimination validity, each scales' criterion-related concurrent validity was supposed to have been obtained by correlating the scale's subscales with similar subscales in other relevant psychological instruments such as the Minnesota Multiphasic Personality Inventory, MMPI-2 (Hathaway \& McKinley, 1989), the Symptoms Checklist, SCL-90-R (Derogatis, 1977), the Coping Inventory for Stressful Situations, CISS (Endler \& Parker, 1990), and the revised Culture-Free Self-Esteem Inventory, CFSEI-2 (Battle, 1992) to demonstrate the scale's conceptual clarity and relationship with identical measures in a Brunei sample. Despite these limitations, the study yielded results that were deemed (by investigators) informative and insightful to regular and special teachers, school counsellors and psychologists, educational researchers, as well as parents in Brunei and elsewhere.

\section{References}

Ahmad, A. (2001). Mathematics for slow learners. In K. Y. Wong, \& M. A. K. Clements (Eds.), Energising science, mathematics, and technical education for all: Proceedings of the sixth annual conference of the Department of Science and Mathematics Education (pp. 138-147). Gadong: University of Brunei Darussalam.

Alatorre A. S., \& Reyes, R. L. (1999). Psychological stress, internalized symptoms and academic achievement of Hispanic adolescents. Journal of Adolescent Research, 14, 343-358. http://dx.doi.org/10.1177/0743558499143004 
Anit, S., \& Suffolk, J. (2001). Investigating understanding by primary six pupils of word problems involving multiplicationand division. In K. Y. Wong, \& M. A. K. Clements (Eds.), Energising science, mathematics, and technical education for all: Proceedings of the sixth annual conference of the Department of Science and Mathematics Education (pp. 290-300). Gadong: University of Brunei Darussalam.

Aryana, M. (2010). Relationship between self-esteem and academic achievement amongst pre-university students. Journal of Applied Sciences, 10(20), 2474-2477. http://dx.doi.org/10.3923/jas.2010.2474.2477

Bai, H. (2011). Cross-validating a bi-dimensional mathematics anxiety scale. Assessment, 18(1), 115-122. http://dx.doi.org/10.1177/1073191110364312

Bai, H., Wang, L., Pan, W., \& Frey, M. (2009). Measuring mathematics anxiety: Psychometric analysis of a bi-dimensional affective scale. Journal of Instructional Psychology, 36, 185-193.

Battle, J. (1992). Culture-free self-esteem inventories. Austin, TX: Pro Education.

Baumeister, R. F., Campbell, J. D., Krueger, J. I., \& Vohs, K. D. (2003). Does high self-esteem cause better performance, interpersonal success, happiness, or healthier lifestyles? Psychological Science in the Public Interest, 4(1), 1-44. http://dx.doi.org/10.1111/1529-1006.01431

Broussard, S. C. (2002). The relationship between classroom motivation and academic achievement in first and third graders. Master of Science (MS) Thesis. Agricultural and Mechanical College. Louisiana State University.

Burns, R. B. (2000). Introduction to research methods (4th ed.). Frenchs Forest, Australia: Longman.

Burton, L., \& Nelson, L. (2010). The relationships between personal resources, proactive coping, personal outcomes and academic success in first year students. Abstracts of the 27th International Congress of Applied Psychology. Melbourne, Australia. 11-16 July 2010. Symposia page 588.

Chin, K. S., \& Clements, M. A. K. (2001). O-level students' understanding of lower secondary school geometry. In W. K. Yoong \& M. A. K. Clements (Eds.), Energising science, mathematics, and technical education for all: Proceedings of the sixth annual conference of the Department of Science and Mathematics Education (pp. 213-222). Gadong: University of Brunei Darussalam.

Chiu, M. S. (2012). Identification and assessment of Taiwanese children's conceptions of learning mathematics. International Journal of Science and Mathematics Education, 10, 163-191. http://dx.doi.org/10.1007/s10763-011-9283-2

Daneshamooz, S., \& Alamolhodaei, H. (2012). Cooperative learning and academic hardiness on students' mathematical performance with different levels of mathematics anxiety. Educational Research, 3(3), 270-276.

Derogatis, L. R. (1977). The SCL-90-R manual I: Scoring, administration and procedure for the SCL-90-R. Baltimore, MD: Clinical Psychometric Research.

Endler, N. S., \& Parker, J. D. A. (1990). Coping Inventory for Stressful Situations, CISS. North Tonawanda, NY: Multi-Health Systems.

Engelbrecht, P., Green, L., Naicker, S., \& Engelbrecht, L. (1993). Inclusive education in action in South Africa. Pretoria: J. L. van Schaik.

Fleming, J. S., \& Courtney, B. E. (1984). The dimensionality of self-esteem, II. Journal of Personality and Social Psychology, 46, 404-421. http://dx.doi.org/10.1037/0022-3514.46.2.404

Fogiel, M. (1989). The psychology problem solver. Piscataway, NJ: Research and Education Association.

Ford, D. Y. (1993). An investigation of paradox of under achievement among gifted black students. Roeper Review, 16(2), 78- 84. http://dx.doi.org/10.1080/02783199309553544

Greenglass, E. R., Schwarzer, R., Jakubiec, D., Fiksenbaum, L., \& Taubert, S. (1999). The proactive coping inventory, PCI): A multidimensional research instrument. Retrieved May 10, 2012, from http://www.userpage.fu-berlin.de/ health/greenpci.htm

Haq, F. S., \& Mundia, L. (2012). Comparison of Brunei pre-service student teachers' attitudes to inclusive education and specific disabilities: Implications for teacher education. Journal of Educational Research, 105(5), 366-374.

Harper, N., \& Daane, C. (1998). Causes and reduction of math anxiety in pre-service elementary teachers. Action in Teacher Education, 19(4), 29-38. http://dx.doi.org/10.1080/01626620.1998.10462889 
Hathaway, S. R., \& McKinley, J. C. (1989). Minnesota Multiphasic Personality Inventory, MMPI-2. Minneapolis, MN: University of Minnesota Press.

Horowitz, M., Wilner, N., \& Alvarez, W. (1979). Impact of event scale: A study of subjective stress. Psychosomatic Medicine, 41, 209.

Kirkpatrick, L. A., \& Feeney, B. C. (2011). A simple guide to SPSS for version 17.0. Belmont, CA: Wadsworth.

Ladis, Z. (2009). Teaching skills blamed for poor maths. The Brunei Times, 22, 2.

Malik, P. R., \& Balda, S. (2006). High IQ adolescents under stress: Do they perform, Poorly? Anthropologist, $8(2), 61-62$.

Martinez, J. G. A. (1987). Preventing math anxiety: a prescription. Academic Therapy, 23(2), 117-125.

Mathison, M. (1977). Curricular interventions and programming innovations for the reduction of mathematics anxiety. ERIC database (\#ED154430).

Ministry of Education. (1997). Special Education Policy Guidelines. Bandar Seri Begawan: Unit Pendidikan Khas.

Ministry of Education. (2007). Proposed SPN21 curriculum: Draft. Bandar Seri Begawan: Curriculum Development Division, Ministry of Education.

Ministry of Education. (2008). ADHOC Committee on Education Programme for Gifted, Students. Bandar Seri Begawan: Unit Pendidikan Khas.

Mohd, L. (2007). Ministry's concerns over decline in good exam results. Borneo Bulletin, May 2, page 8.

Moore, B. J. (1997). Three case studies of gifted students who underachieve in high school. Dissertation Abstract International Section A: Humanities and Social Sciences, 57(6-A), 3394.

Mundia, L. (2009). Implementation of inclusive education in Brunei Darussalam: Review of possible implications on school counsellors. Electronic Journal for Inclusive Education, 2(4), Spring/Summer Issue.

Mundia, L. (2010a). Problems in learning mathematics: Comparison of Brunei junior high, school students in classes with and without repeaters. Journal of Mathematics Research, 2(3), 150-160.

Mundia, L. (2010b). Implementation of SPN21 curriculum in Brunei Darussalam: A review,of selected implications on school assessment reforms. International Education Studies, 3(2), 119-129.

Mundia, L. (2012a). The Assessment of Mathematics Learning Difficulties in a Primary, Grade 4 Child with High Support Needs: Mixed Methods Approach. International Electronic Journal of Elementary Education, 4(2), 347-366.

Mundia, L. (2012b). Policy changes in Brunei teacher education: Implications for the, selection of trainee teachers. The Education Forum, 76(3), 326-342. http://dx.doi.org/10.1080/00131725.2012.682489

Mundia, L. (2012c). Assessment of GenNEXT learning outcomes at the University of Brunei Darussalam: A qualitative review of selected opportunities, benefits and challenges in human resource development. Journal of International Education and Leadership, 2(3).

Nixon, J., Maccann, C., \& Lipnevich, A. (2010). Students' approaches to coping with stress, can impact their academic achievement. Abstracts of the 27th International Congress of Applied Psychology. Melbourne, Australia. 11-16 July 2010. Symposia pages 588-589.

Onwuegbuzie, A. J. (2001). I will begin my statistics assignment tomorrow: The relationship, between statistics anxiety and academic procrastination. Retrieved May 21, 2012, from http://www.fearofstatisticscourse.htm

Rajagopal, S. D., \& Bakar, A. A. (2004). Improving students' attitudes towards mathematics by changing classroom learning environment through cooperative learning strategy. In I. P. A. Cheong, H. S. Dhindisa, I. J. Kyeleve, \& O. Chukwu (Eds.), Globalisation trends in science, mathematics and technical education: Proceedings of the annual conference of the Department of Science, Mathematics and Technical Education (pp. 259-268). Gadong: University of Brunei Darussalam.

Richardson, F. C., \& Suinn, R. M. (1972). The mathematics anxiety rating scale: Psychometric data. Journal of Counseling Psychology, 19(6), 551-554. http://dx.doi.org/10.1037/h0033456

Rickets, J. C. (2003). The efficacy of leadership development, critical thinking dispositions and student academic performance on the critical thinking skills of selected youth leaders. Doctor of Philosophy (PhD) Dissertation. Graduate School. University of Florida. 
Rosenberg, M. (1965). Society and the adolescent self-image. Princeton, NJ: Princeton University Press.

Sagiea, A. (1994). Assessing achievement motivation: Construction and application of a new scale using Elizur's multifaceted approach. The Journal of Psychology: Interdisciplinary and Applied, 128(1), 51-61. http://dx.doi.org/10.1080/00223980.1994.9712711

Selye, H. (1974). The stress of life. New York: McGraw-Hill.

Sloan, T. R. (2010). A quantitative and qualitative study of mathematics anxiety among pre-service teachers. The Educational Forum, 74(3), 242-256. http://dx.doi.org/10.1080/00131725.2010.483909

Somerset, H. C. A. (1987). Examination Reform: The Kenya Experience. Report No. 64. A Report Prepared for the World Bank. Sussex: IDS.

Tait, K., \& Mundia, L. (2012). Preparing teachers to meet the challenges of inclusive education in Negara Brunei Darussalam. In C. I. Forlin (Ed.), Future directions for inclusive teacher education: An international perspective (pp. 60-69). Hong Kong: Routledge/Francis \& Taylor.

Tassie, S., \& Whelan, T. (2007). Mainland Chinese students in Australia: The potential for stress-related growth. Journal of Psychology in Chines Societies, 8(1), 71-90.

Tella, A. (2007). The impact of motivation on students' academic achievement and learning outcomes in mathematics among secondary school students in Nigeria. European Journal of Mathematics, Science and Technology, 3, 149-156.

Trujillo, K. M., \& Hadfield, O. D. (1999). Tracing the roots of mathematics anxiety through in-depth interviews with pre-service elementary teachers. College Student Journal, 33(2), 219-233.

Vaiyatvutjamai, P., \& Clements, M. A. K. (2004). Analysing errors made by middle school students on six linear inequations tasks. In I. P. A. Cheong, H. S. Dhindisa, I. J. Kyeleve, \& O. Chukwu (Eds.), Globalisation trends in science, mathematics and technical education: Proceedings of the annual conference of the Department of Science, Mathematics and Technical Education (pp. 173-182). Gadong: University of Brunei Darussalam.

Veloo, P. K., \& Diah, A. H. M. (2004). Instrumental instruction and its influence on development of number sense. In I. P. A. Cheong, H. S. Dhindisa, I. J. Kyeleve, \& O. Chukwu (Eds.), Globalisation trends in science, mathematics and technical education: Proceedings of the annual conference of the Department of Science, Mathematics and Technical Education (pp. 183-192). Gadong: University of Brunei Darussalam.

Williams, W. V. (1988). Answers to questions about mathematics anxiety. School Science and Mathematics, 88 , 95-104. http://dx.doi.org/10.1111/j.1949-8594.1988.tb11786.x

Wong, K. Y., Omar, K., \& Mak, L. Y. F. (2004). Mathematics performance of preschoolers in Brunei Darussalam. Brunei Darussalam Journal of Special Education, 1, 29-40.

Zhu, Y., \& Leung, F. K. S. (2011). Motivation and achievement: Is there an East Asian model? International Journal of Science and Mathematics Education, 9, 1189-1212. http://dx.doi.org/10.1007/s10763-010-9255-y

\section{Copyrights}

Copyright for this article is retained by the author(s), with first publication rights granted to the journal.

This is an open-access article distributed under the terms and conditions of the Creative Commons Attribution license (http://creativecommons.org/licenses/by/3.0/). 